\title{
The Use of Children as a Tactic of Intimate Partner Violence and its Relationship to Survivors' Mental Health
}

\author{
Kathryn A. V. Clements ${ }^{1} \cdot$ Mackenzie Sprecher $^{1} \cdot$ Sydney Modica $^{1} \cdot$ Michelle Terrones $^{1} \cdot$ Katie Gregory $^{1}$. \\ Cris M. Sullivan ${ }^{1}$
}

Accepted: 28 September 2021 / Published online: 7 October 2021

(c) The Author(s) 2021

\begin{abstract}
Although prior research has established that intimate partner violence (IPV) often leads to increased depression, anxiety and post-traumatic stress disorder (PTSD), little is known about how often abusive partners and ex-partners use survivors' children as an abuse tactic, nor whether this form of IPV also is detrimental to survivors' mental health. The current study interviewed 299 unstably housed survivors of intimate partner violence shortly after they sought services from a domestic violence agency. All participants were parents of minor children. In-person interviews asked about abuse experienced in the prior six months, including the ways children were used as a form of IPV. Participants were also asked about their current depression, anxiety, and symptoms of PTSD. As hypothesized, the majority of parents reported their abusive partners and ex-partners had used their children as a form of IPV to control and hurt them. Further, after controlling for other forms of IPV, use of the children significantly predicted both increased anxiety and greater number of PTSD symptoms. Results show the importance of focusing on the use of children as a common and injurious form of abuse used against survivors of intimate partner violence (IPV).
\end{abstract}

Keywords Children $\cdot$ Domestic violence $\cdot$ Control $\cdot$ Mental health

Prior research has demonstrated a strong and negative relationship between intimate partner violence (IPV) and mental health consequences for survivors. Victimization through physical and emotional abuse (Ahmadabadi et al., 2020; Ellsberg et al., 2008; Mapayi et al., 2013; Rivera, 2018) and economic abuse (Adams \& Beeble, 2019; Stylianou, 2018) have all been shown to lead to increased depression, anxiety and post-traumatic stress disorder (PTSD). Another form of IPV that has been understudied but that appears to be quite prevalent against survivors who are parents, is the abusive partner's use of the children (UOC) to control or harm their current or former partner (Bancroft et al., 2011; Beeble et al., 2007). To fill this void, the current study examined how often this form of IPV was used against a sample of 299 unstably housed IPV survivors, and if such abuse impacted survivor mental health.

Kathryn A. V. Clements

vadnais3@msu.edu

1 Michigan State University, East Lansing, MI, USA

\section{Intimate Partner Violence and Its Impact on Mental Health}

Intimate partner violence is both pervasive and devastating worldwide (Garcia-Moreno et al., 2006; World Health Organization, 2013). In the United States, more than one in four women and one in six men have been victimized by their partners (Breiding et al., 2015). IPV can include physical, emotional, sexual and/or economic abuse, and is used as a tactic to control and hurt partners and ex-partners (Adams et al., 2008; Bancroft et al., 2011; Loxton et al, 2013). In addition, stalking encompasses a range of behaviors employed to bother, intimidate, and/or monitor someone, either in person, through other people, or via technology (Bancroft et al., 2011; Loxton et al., 2013; Maddox, 2015).

These common forms of IPV victimization have been shown to lead to increased survivor depression, anxiety, and PTSD (Ahlfs-Dunn \& Huth-Bocks, 2015; Ahmadabadi et al., 2020; Beydoun et al., 2012; Bonomi et al., 2006; Nathanson et al., 2012; Rivera et al., 2018). Far less is known, however, about how often perpetrators use children as a tactic of IPV and whether this behavior also 
leads to depression, anxiety, or PTSD. The scant research conducted on this topic to date suggests that this tactic is indeed both common and injurious. In one of the first studies to examine this phenomenon, Beeble and colleagues (2007) interviewed 156 survivors of IPV with a schoolaged child and found that almost $90 \%$ reported that their children had been used as a control tactic by their abuser. They also found this was more frequent when the abuser was the biological father of the child(ren), when the survivors had ended or were ending the relationship, and when there was court-ordered visitation in place. Moreover, Rivera and colleagues (2018) conducted a longitudinal study with 40 IPV survivors who had separated or were in the process of separating from the abusive partner, and who had minor children in common with the perpetrator. They found that UOC as a form of IPV significantly predicted both depression and PTSD in the survivors over time.

Further qualitative support exists for the UOC as a postseparation IPV tactic (Feresin et al, 2019; Gregory, 2016; Rivera et al., 2018). Toews and Bermea (2017) interviewed twenty-two women who had separated from their husbands after experiencing IPV and found all of the women experienced continued power and control tactics by their abuser after separation. Among the tactics discussed, the most common form identified by the women was UOC (examples included neglecting the children's needs in order to cause the other parent pain and threatening to kidnap the children). Feresin and colleagues (2019) reported that almost $80 \%$ of their sample of 151 IPV survivors, who were also parents, reported the abuser had used some kind of threat or manipulation against them involving their children.

\section{Current Study}

The current study aimed to elucidate how the abuser's UOC as a form of IPV related to other types of abuse (physical, emotional, sexual, and stalking) and the extent of a relationship between UOC as an abuse tactic and survivor mental health. This operationalization of UOC as a tactic of IPV and its impact on survivors is not to diminish the impact of such tactics on children. However, the scope of the current study is limited to adult survivors. In-person interviews with 299 unstably housed IPV survivors who were also parents of minor children included foci on prior IPV experienced - including the use of the children - as well as current depression, anxiety and PTSD. We hypothesized that survivors would experience UOC abuse at similar rates to other forms of abuse, and that such abuse would be positively related to parents' depression, anxiety, and PTSD in linear regression models.

\section{Method}

The current study is part of a longitudinal evaluation of the effectiveness of domestic violence (DV) support services in helping unstably housed IPV survivors obtain safe and stable housing. Data for this study come from baseline data from the larger study, collected shortly after survivors contacted a DV agency for help. The full sample included survivors from five DV organizations within a Pacific Northwest state in the United States. Survivors were eligible to participate if they were a recent adult victim of intimate partner violence and were homeless or unstably housed. Clients were invited by agency staff to participate in the study shortly after they enrolled in services. For the current study, we examined only data of participants who were parenting a child under the age of $18(n=299)$. This study received University Institutional Review Board approval.

\section{Demographics}

The women $(n=292 ; 98 \%)$ and men $(n=7 ; 2 \%)$ in the study ranged from 19 to 57 years of age $(M=33.2$; $S D=7.95)$. The majority of participants identified as either Hispanic/Latinx (32.1\%) or Non-Hispanic White (33.1\%). The remaining participants identified as African American/Black (15.1\%), US Indigenous (4.7\%), of Asian descent (1.3\%), and/or Middle Eastern $(<1 \%)$. Of those survivors reporting a racial/ethnic minority $(n=200)$, $21 \%$ were multiracial or multi-ethnic. Most of the participants identified as heterosexual (86.6\%). Most participants (92\%) reported no longer being in a relationship with the abuser at the time of the interview. Forty-three percent of survivors reported raising one child, forty-six percent of survivors reported raising two to three children and twelve percent reported raising four or more children. Child average age was 7.3 years old.

\section{Procedure}

In-person interviews were conducted with survivors in English (83.3\%) or Spanish (16.7\%), according to participant preference. Participants were compensated with $\$ 50$ for their time. Interviews ranged from $43 \mathrm{~min}$ to $3 \mathrm{~h}$ and $13 \mathrm{~min}$, with an average length of $1 \mathrm{~h}$ and $15 \mathrm{~min}$.

\section{Measures}

In addition to demographic questions, data for the current study included questions about multiple forms of IPV the participant may have experienced in the prior six months, as well as their current levels of depression, anxiety, and 
PTSD symptoms. Details for each measure used in the current study are described below.

\section{Intimate Partner Violence}

Physical violence, emotional abuse, sexual abuse, and stalking were assessed using the Composite Abuse Scale (CAS), which was slightly modified for the current study (Hegarty et al., 1999; Loxton et al., 2013). Reliability analyses have demonstrated high internal consistency of the CAS. This scale was modified through the addition of the items "strangle you," "stalk you," "demand sex whether you wanted to or not" and "force sexual activity," to capture the abusive experiences of survivors more fully. In addition, two original items ("hang around outside your house" and "harass you at work" were replaced with the item "repeatedly follow you, phone you, and/or show up at your house/work/other place" to capture the abusive stalking experiences of survivors who may not be living with the abuser.

Questions were asked within the format: "How often, if at all, did [abuser]: ..." The original response options for the CAS were "daily," "once per week," "once per month," "several times," "only once," and "never." These were modified for this study to match interviews occurring every six months. The response options for the current study ranged from $0-5: 0=$ "never," $1=$ "once," $2=$ "several times or between $2-3 \times$ in the last 6 months," $3=$ "once a month," $4=$ "once a week," and $5=$ "daily." The total CAS score, comprised of 31 items, demonstrated high internal reliability. Cronbach's alpha for the full scale was $0.95(M=1.64$, $S D=1.07)$.

\section{Abuser's Use of Children as a Form of IPV}

The frequency with which abusers used the participants' children against them as a form of manipulation or control was assessed using the 7-item Use of the Children Scale (Beeble et al., 2007). The scale consisted of items measuring how often in the previous six months the abuser had used the children to stay in the survivors' lives, harass, intimidate, track, or frighten them, as well as tried to turn the kids against them or convince the survivor to take the abuser back and resume the relationship. Response options ranged from 0 (never) to 4 (quite often). Cronbach's alpha for the scale was $0.84(M=1.76, S D=1.12)$.

\section{Mental Health}

Depression Depression was assessed using the 9-item Patient Health Questionnaire (PHQ-9; Kroenke et al., 2001). Participants were asked about the frequency of depressive symptoms (e.g., "feeling down, depressed, or hopeless") over the previous two weeks using a 4-point Likert scale ranging from 0 (not at all) to 3 (nearly every day). Cronbach's alpha for the measure was $0.88(M=1.38, S D=0.76)$.

Anxiety Anxiety was assessed using the 7-item Generalized Anxiety Disorder measure (GAD-7; Spitzer, Kroenke, $\&$ Williams, 2006). Participants were asked about the frequency of anxious feelings (e.g., "not being able to stop or control worrying") over the previous two weeks using a 3-point Likert scale ranging from 0 (not at all) to 3 (nearly every day). Reliability was good, with Cronbach's alpha of $0.89(M=1.69, S D=0.93)$.

Post-Traumatic Stress Post-traumatic stress symptomatology was assessed using the 10-item Trauma Screening Questionnaire (TSQ; Brewin et. al., 2002). Participants were asked about their physical or emotional responses to trauma (e.g., "being jumpy or being startled at something unexpected; upsetting thoughts about the event that have come into your mind against your will") in the prior week. Responses were 0 (no) and 1 (yes); a score of 6 or higher indicates the likelihood of experiencing PTSD. Cronbach's alpha for the measure was $0.76(M=0.67, S D=0.26)$.

\section{Analysis}

To examine how UOC related to survivors' depression, anxiety, and PTSD, ordinary linear regression analyses were performed using depression, anxiety, and PTSD symptoms as dependent variables and UOF abuse tactic as the independent variable. The Composite Abuse Scale (measuring other forms of IPV) was used as a control variable in all analyses. Analyses were performed using IBM SPSS Statistics (Version 26). No variable had more than $2 \%$ missing data, and Little's MCAR test indicated that missing data was completely at random, $\chi^{2}(17,299)=11.07, p=0.853$; therefore listwise deletion was used in analyses.

\section{Results}

\section{Extent of Abusers' UOC and other Forms of IPV}

As hypothesized, most participants (88\%) reported that their abusers had used their children as a tactic to control, harm or monitor them within the prior six months. Abusers used the participants' children to stay in their lives (76\%), intimidate them (72\%), keep track of them (72\%), harass them (71\%), or frighten them $(69 \%)$. Many also tried to turn the children against them (62\%), or used the children to convince survivors to take them back and resume the relationship (45\%).

Participants also reported experiencing a great deal of other forms of IPV in the prior six months. Specifically, they experienced high rates of emotional abuse (96\%), physical violence 
(92\%), stalking (91\%), and sexual abuse (52\%). Table 1 presents a summary of descriptive statistics, including means, standard deviations, scale alphas, and correlations among measures.

\section{Abuser's Use of Children Predicting Survivor Mental Health}

As expected, depression, anxiety and PTSD symptoms were significantly and positively correlated with each other and with the CAS abuse scale (see Table 1). To examine how UOC was related to mental health outcomes, the first regression model tested whether UOC predicted depression after controlling for other forms of IPV. Consistent with prior studies, physical violence, emotional abuse, sexual abuse, and stalking predicted depression, $F(2,294)=9.299, p<0.001)$ with $R^{2}=0.060$. Using $R$-squared as a measure of effect size suggests the effect of UOC on depression scores is small (between 0.02 and 0.13 ; Ellis, 2010). After controlling for this variance, the UOC did not explain additional variance to survivors' depression scores.

In the second regression, the UOC tactics did significantly predict anxiety after controlling for other forms of IPV. Here, a significant amount of variance in anxiety scores was explained by the UOC, $F(2,294)=14.244, p<0.001$ with $R^{2}=0.089$. Again, using $R$-squared as a measure of effect size suggests that UOC had a small effect on survivor anxiety scores (Ellis, 2010).

The third regression examined whether UOC predicted PTSD. After controlling for other forms of IPV, UOC significantly predicted total PTSD symptoms, $F(2,294)=14.704$, $p<0.001, R^{2}=0.091$. Looking at R-squared, UOC also had a small effect on PTSD symptomology (Ellis, 2010). Table 2 details the three regressions. Included are the unstandardized regression coefficients, standard errors, $t$-scores, $p$-values, and $95 \%$ confidence intervals for the independent and control variables.

\section{Discussion}

The current study supports the need to investigate UOC as a common and damaging form of abuse perpetrated against parents experiencing IPV. Survivors' experience of this form of IPV was not only extremely common, but explained anxiety and PTSD symptoms above and beyond other common forms
Table 2 Regressions of use of children on survivors' mental health

\begin{tabular}{|c|c|c|c|c|c|}
\hline Variable & $B$ & $S E$ & $t$ & $p$ & $95 \% \mathrm{CI}$ \\
\hline \multicolumn{6}{|l|}{ Depression } \\
\hline Composite Abuse & 0.13 & 0.04 & 3.00 & 0.003 & {$[.045, .219]$} \\
\hline Use of Child & 0.07 & 0.04 & 1.64 & 0.103 & {$[-.014, .153$} \\
\hline \multicolumn{6}{|l|}{ Anxiety } \\
\hline Composite Abuse & 0.18 & 0.05 & 3.50 & 0.001 & {$[.081, .288]$} \\
\hline Use of Child & 0.12 & 0.05 & 2.28 & 0.023 & {$[.016, .216]$} \\
\hline \multicolumn{6}{|l|}{ PTSD Symptomology } \\
\hline Composite Abuse & 0.05 & 0.02 & 3.31 & 0.001 & {$[.020, .077]$} \\
\hline Use of Child & 0.04 & 0.01 & 2.60 & 0.010 & {$[.009, .064]$} \\
\hline
\end{tabular}

of abuse, although the effect sizes were small. These findings add to a small but growing body of research examining the prevalence and impact of UOC as a common form of IPV (e.g., Beeble et al., 2007; Dragiewicz et al., 2021; Feresin et al., 2019; Rivera et al., 2018).

Consistent with prior research, this study found that other forms of IPV (physical, emotional, sexual, and stalking) all led to increased depression, anxiety, and PTSD symptomatology (Ahlfs-Dunn \& Huth-Bocks, 2015; Ahmadabadi et al., 2020; Beydoun et al., 2012; Bonomi et al., 2006; Nathanson et al., 2012; Rivera et al., 2018). After controlling for this association, UOC also predicted increased anxiety and PTSD, although this was not the case for depression.

The association between UOC as a control tactic and parental anxiety is not surprising. In the current study, we measured Generalized Anxiety Disorder (GAD), which is characterized by excessive and ongoing worry. Increased anxiety (e.g., worry) was likely due to the parent fearing for their children's safety and well-being as a result of this uniquely damaging form abuse. Similarly, knowing that the perpetrator is involving the children as a form of abuse likely involves its own, separate trauma experience or at the very least can exacerbate trauma responses. If the abused parent feels unable to stop the tactic involving using the children (whether due to sharing custody or visitation, or otherwise being unable to prevent access to the children), this can lead to greater feelings of anxiety and helplessness.
Table 1 Descriptive statistics and correlations for study variables

\begin{tabular}{llllllll}
\hline Variable & $M$ & $S D$ & 1 & 2 & 3 & 4 & 5 \\
\hline 1. Depression & 1.38 & 0.76 & & & & & \\
2. PTSD Symptoms & 0.67 & 0.26 & $.635^{* *}$ & & & & \\
3. Anxiety & 1.69 & 0.93 & $.806^{* *}$ & $.679^{* *}$ & & & \\
4. Composite Abuse & 1.64 & 1.07 & $.226^{* *}$ & $.260^{* *}$ & $.269^{* *}$ & & \\
6. Use of Child & 1.76 & 1.12 & $.177^{* *}$ & $.242^{* *}$ & $.228^{* *}$ & $.402^{* *}$ & -0.108 \\
\hline
\end{tabular}

** Correlation is significant at the 0.01 level (2-tailed) 
The current study did not find a relationship between UOC and parental depression. This could be due to the fact that other forms of abuse were so highly correlated with depression that this particular form of abuse did not explain enough additional variance to rise to a level of significance. It could also be due to limitations with the depression measure used in this study. The PHQ-9 measures Major Depressive Disorder, which is the extent to which someone is experiencing overwhelming feelings of sadness or a lack of interest and pleasure in activities. It is plausible that, while having children used against them leads to greater worry, anxiety and trauma responses, it does not - over and above other forms of abuse - lead to more sadness or lack of pleasure in activities. There might be a clinical plateau in this regard among this already at-risk group. More research is needed to better elucidate these effects.

\section{Limitations}

Findings should be considered in light of study limitations. This study did not include questions about which parent had custody of the children, for example, although previous work has found this information can be helpful for understanding effects that are observed (Elizabeth, 2017; Kernic et al., 2005). Joint custody can provide additional opportunities to decrease survivors' mental health and safety, and often involves threats to take or keep the children, using the children as sources of information about the survivor, prolonged custody battles, or using the children's visitations as a way to track the survivor (Beeble et al., 2007; Feresin et al., 2019; Rivera et al., 2018).

The larger research study from which these data were derived also focused on IPV survivors who were either homeless or unstably housed, limiting the generalizability of these findings. All participants had also sought services, so findings cannot be generalized to IPV survivors who do not seek help from domestic violence agencies. Finally, although the study sample was somewhat racially and ethnically diverse (approximately one third Latinx, one third white, and 15\% African American), additional studies are needed with more diverse samples. This sample was almost entirely cisgender, heterosexual women, as well, limiting our knowledge about male survivors, trans-survivors, and those in same sex relationships.

The study was also cross-sectional, preventing us from confidently discussing causality. While the expectation is that IPV and UOC led to greater mental distress, longitudinal studies are needed to demonstrate temporality.

\section{Implications for Practice and Research}

UOC as a manipulation tactic appears to be commonly used and deleterious to survivors' mental health, and deserves more attention. Many IPV service providers already consider the presence of children when working with survivors, and our findings encourage practitioners to add another dimension to that by considering interventions that would specifically protect survivors from tactics by abusers involving children or offer support for these experiences. One example of this is legal advocacy. There is evidence that custody stalking is an intentional effort to interfere with legal proceedings pursued by survivors of abuse (Elizabeth, 2017). Clear documentation of the ways in which survivors experience UOC as just one type of abuse IPV may support the protection of survivors and their children from post-separation abuse. This could also include providing continuous social support opportunities and resources around custody and/or visitation requirements and agreements (Guyon-Harris et. al, 2017). For example, Hayes (2017) found that mothers who had recently separated from an abusive partner were four times more likely to report threats involving the children than mothers who had stayed in the relationship. Hayes (2017) argued that findings like these should be considered in custody proceedings. Hayes' work supports previous findings that in some custody situations, abusive partners who were never previously involved with children use custody proceedings as a low-risk opportunity to maintain control and coerce the survivor into maintaining contact, as the family welfare system currently places a high value on children's relationship with both parents (Bancroft \& Silverman, 2002). Legal advocacy to support survivors navigating the legal system may decrease some of the anxiety and trauma experienced during these situations.

Practitioners should consider tailoring services to specific parenting needs and experiences. Previous literature has found that enhancing a survivor's emotional and physical well-being can improve their perceived role as a parent (Collins et al, 2015). Practitioners should also consider using and creating services that benefit both parent and child. Services aimed at building parents' and children's emotional literacy and providing resources on coping with emotions healthily and has been shown to increase both parent and adult survivor well-being (Collins et al, 2015).

The current study also has research implications. This is the largest sample size to date in which researchers have measured UOC as an abuse tactic. However, expanding this area of research to also include tactics such as custody stalking, the coercive use of legal child custody proceedings to track a survivor parent, may provide a more holistic understanding of the ways in which abusers use children to control or manipulate current or former partners. For example, current studies on custody stalking include smaller sample sizes (ranging from a sample of 12 to a sample of 151), and larger samples may provide more insight into the frequency of using children as a tactic. Larger studies can also be a way 
for researchers to gain more information about abusers' use children over time and how this affects survivors' psychological and emotional well-being.

We also echo the call for children to be included as participants in studies about their experiences with abuse (e.g., Dragiewicz et al., 2021; Øverlien \& Holt, 2019). Researchers should consider a myriad of ways children can be reached and manipulated, especially with expanding access to technology (Dragiewicz et al., 2021). Our current perspective on the post-separation abuse tactics described in this study are limited to the adult perspective. It is likely, however, that UOC may have similar and significant effects on children's mental health as well, and understanding these impacts are an important part of designing and promoting effective interventions. Study designs that include survivors from diverse geographic areas with different legal options and local policies and practices would also shed light on the specific effects of this type of abuse in differing contexts.

\section{Conclusion}

This study, albeit limited in scope, provides insight into the mental health consequences when abusive partners and expartners use survivors' children as a form of control and manipulation. Ideally, this exploratory research is just the beginning of numerous studies, with diverse populations, examining UOC as a form of IPV with its own detrimental outcomes.

\begin{abstract}
Acknowledgements This research was supported by a subcontract from the Washington State Coalition Against Domestic Violence, who received funding through a contract with the U.S. Department of Health and Human Services' Office of the Assistant Secretary for Planning and Evaluation (ASPE) in partnership with the Department of Justice's Office for Victims of Crime [contract \#HHSP233201600070C], and by a grant from the Washington State Coalition Against Domestic Violence, who received funding from The Bill \& Melinda Gates Foundation [\#OPP1117416]. Points of view do not necessarily represent the position or policies of the funders.
\end{abstract}

Open Access This article is licensed under a Creative Commons Attribution 4.0 International License, which permits use, sharing, adaptation, distribution and reproduction in any medium or format, as long as you give appropriate credit to the original author(s) and the source, provide a link to the Creative Commons licence, and indicate if changes were made. The images or other third party material in this article are included in the article's Creative Commons licence, unless indicated otherwise in a credit line to the material. If material is not included in the article's Creative Commons licence and your intended use is not permitted by statutory regulation or exceeds the permitted use, you will need to obtain permission directly from the copyright holder. To view a copy of this licence, visit http://creativecommons. org/licenses/by/4.0/.

\section{References}

Adams, A. E., Sullivan, C. M., Bybee, D., \& Greeson, M. R. (2008). Development of the Scale of Economic Abuse. Violence Against Women, 14(5), 563-588. https://doi.org/10.1177/2F10778012 08315529

Ahlfs-Dunn, S. M., \& Huth-Bocks, A. C. (2015). Intimate partner violence involving children and the parenting role: Associations with maternal outcomes. Journal of Family Violence, 31(3), 387-399. https://doi.org/10.1007/s10896-015-9791-x

Ahmadabadi, Z., Najman, J. M., Williams, G. M., Clavarino, A. M., d'Abbs, P., \& Tran, N. (2020). Intimate partner violence and subsequent depression and anxiety disorders. Social Psychiatry and Psychiatric Epidemiology, 55, 611-620. https://doi.org/10. 1007/s00127-019-01828-1

Bancroft, L., Silverman, J. G., \& Ritchie, D. (2011). The batterer as parent: Addressing the impact of domestic violence on family dynamics: SAGE Publications.

Bancroft, L., \& Silverman, J. (2002). The batterer as parent: Addressing the impact of domestic violence on family dynamics. Sage.

Beeble, M., Bybee, D., \& Sullivan, C. (2007). Abusive men's use of children to control their partners and ex-partners. European Psychologist, 12(1), 54-61. https://doi.org/10.1027/1016-9040. 12.1.54

Beydoun, H. A., Beydoun, M. A., Kaufman, J. S., Lo, B., \& Zonderman, A. B. (2012). Intimate partner violence against adult women and its association with major depressive disorder, depressive symptoms and postpartum depression: A systematic review and meta-analysis. Social Science \& Medicine, 75(6), 959-975. https://doi.org/10.1016/j.socscimed.2012.04.025

Bonomi, A. E., Thompson, R. S., Anderson, M., Reid, R. J., Carrell, D., Dimer, J. A., \& Rivara, F. P. (2006). Intimate partner violence and women's physical, mental, and social functioning. American Journal of Preventive Medicine, 30(6), 458-466. https://doi.org/10.1016/j.amepre.2006.01.015

Breiding M. J., Basile, K. C., Smith, S. G., Black, M. C., Mahendra, R. R.. Intimate partner surveillance: Uniform definitions and recommended data elements, version 2.0. (2015). National Center for Injury Prevention and Control, Centers for Disease Control and Prevention. https://www.cdc.gov/violenceprevent ion/pdf/intimatepartnerviolence.pdf

Carlson, J., Voith, L., Brown, J. C., \& Holmes, M. (2019). Viewing children's exposure to intimate partner violence through a developmental, social-ecological, and survivor lens: The current state of the field, challenges, and future directions. Violence against Women, 25(1), 6-28. https://doi.org/10.1177/10778 01218816187

Chandan, J. S., Thomas, T., Bradbury-Jones, C., Russell, R., Bandyopadhyay, S., Nirantharakumar, K., \& Taylor, J. (2019). Female survivors of intimate partner violence and risk of depression, anxiety and serious mental illness. The British Journal of Psychiatry: The Journal of Mental Science, 1-6. https://doi.org/10.1192/bjp. 2019.124

Collins, K. S., Freeman, P. A. C., Strieder, F. H., Reinicker, P., \& Baldwin, C. (2015). A pilot study examining the reduction of trauma symptomatology in families to prevent child abuse and neglect: Trauma adapted family connections. Journal of Public Child Welfare, 9(5), 506-527. https://doi.org/10.1080/15548732. 2015.1098582

Davoren, M., Kallis, C., González, R. A., Freestone, M., \& Coid, J. W. (2017). Anxiety disorders and intimate partner violence: Can the association be explained by coexisting conditions or borderline personality traits? The Journal of Forensic Psychiatry \& 
Psychology, 28(5), 639-658. https://doi.org/10.1080/14789949. 2016.1172659

Dragiewicz, M., Woodlock, D., Salter, M., \& Hayes, B. (2021). "What's Mum's password?": Australian mothers' perceptions of children's involvement in technology-facilitated coercive control. Journal of Family Violence. https://doi.org/10.1007/s10896-021-00283-4

Elizabeth, V. (2017). Custody stalking: A mechanism of coercively controlling mothers following separation. Feminist Legal Studies, 25(2), 85-201. https://doi.org/10.1007/s10691-017-9349-9

Ellis, P. D. (2010). The essential guide to effect sizes.

Ellsberg, M., Jansen, H. A., Heise, L., Watts, C. H., Garcia-Moreno, C., on behalf of the WHO Multi-country Study on Women's Health and Domestic Violence against Women Study Team, \& WHO Multi-country Study on Women's Health and Domestic Violence against Women Study Team. (2008). Intimate partner violence and women's physical and mental health in the WHO multi-country study on women's health and domestic violence: An observational study. The Lancet, 371(9619), 1165-1172. https://doi.org/10.1016/ S0140-6736(08)60522-X

Feresin, M., Bastiani, F., Beltramini, L, \& Romito, P. (2019) The involvement of children in postseparation intimate partner violence in Italy: A strategy to maintain coercive control?, Affilia: Journal of Women and Social Work 34(4), 481-497. https://doi. org/10.1177/088610991985762

Fleury, R. E., Sullivan, C. M., \& Bybee, D. I. (2000). When ending the relationship does not end the violence: Women's experiences of violence by former partners. Violence against Women, 6(12), 1363-1383. https://doi.org/10.1177/10778010022183695

Fogarty, A., Woolhouse, H., Giallo, R., Wood, C., Kaufman, J., Brown, S. (2019). Mothers experience of parenting within the context of intimate partner violence: Unique challenges and resilience. Journal of Interpersonal Violence, 1-24. https://doi.org/10.1177/ 0886260519883863

Garcia-Moreno, C., Jansen, H. A., Ellsberg, M., Heise, L., \& Watts, C. H. (2006). Prevalence of intimate partner violence: Findings from the WHO multi-country study on women's health and domestic violence. The Lancet, 368(9543), 1260-1269.

Gregory, K. A. (2016). The longitudinal impact of abusers' use of children on IPV survivors' and children's well-being (Publication No. 10246351) [Doctoral dissertation, Michigan State University]. ProQuest Dissertations and Theses Global.

Guyon-Harris, K. L., Ahlfs-Dunn, S., \& Huth-Bocks, A. (2017). PTSD symptom trajectories among mothers reporting interpersonal trauma: Protective factors and parenting outcomes. Journal of Family Violence, 32(7), 657-667. https://doi.org/10.1007/ s10896-017-9934-3

Hamby, S. L., Finkelhor, D., Turner, H. A., \& Ormrod, R. K. (2011). Children's exposure to intimate partner violence and other forms of family violence: Nationally representative rates among US youth. OJJDP Juvenile Justice Bulletin - NCJ 232272. Washington, DC: US Government Printing Office.

Hayes, B. E. (2012). Abusive men's indirect control of their partner during the process of separation. Journal of Family Violence, 27, 333-344. https://doi.org/10.1007/s10896-012-9428-2

Hayes, B. E. (2017). Indirect abuse involving children during the separation process. Journal of Interpersonal Violence, 32(19), 2974-2997. https://doi.org/10.1177/0886260515596533

Hegarty, K., Sheehan, M., \& Schonfeld, C. (1999). A multidimensional definition of partner abuse: Development and preliminary validation of the Composite Abuse Scale. Journal of Family Violence, 14, 399-415. https://doi.org/10.1023/A:1022834215681

Kernic, M. A., Monary-Ernsdorff, D. J., Koepsell, J. K., \& Holt, V. L. (2005). Children in the crossfire: Child custody determinations among couples with a history of intimate partner violence. Violence against Women, 11(8), 991-1021.
Kroenke, K., Spitzer, R. L., \& Williams, J. B. (2001). The PHQ-9: Validity of a brief depression severity measure. Journal of General Internal Medicine, 16(9), 606-613. https://doi.org/10.1046/j. 1525-1497.2001.016009606.x

Laskey, P., Bates, E. A., \& Taylor, J. C. (2019). A systematic literature review of intimate partner violence victimisation: An inclusive review across gender and sexuality. Aggression and Violent Behavior, 47, 1-11. https://doi.org/10.1016/j.avb.2019.02.014

Loxton, D., Powers, J., Fitzgerald, D., Forder, P., Anderson, A., Taft, A., \& Hegarty, K. (2013). The Community Composite Abuse Scale: Reliability and validity of a measure of intimate partner violence in a community survey from the ALSWH. Journal of Women's Health, Issues \& Care 2(4). https://doi.org/10.4172/2325-9795.1000115

Lutgendorf, M. A. (2019). Intimate partner violence and women's health. Obstetrics \& Gynecology, 134(3), 470-480. https://doi. org/10.1097/AOG.0000000000003326

Maddox, L. M. (2015). Young Adults' Perception of Fathering and the Father-Child Relationship in the Context of Marital Violence. Auburn University.

Mapayi, B., Makanjuola, R. O. A., Mosaku, S. K., Adewuya, O. A., Afolabi, O., Aloba, O. O., \& Akinsulore, A. (2013). Impact of intimate partner violence on anxiety and depression amongst women in Ile-Ife, Nigeria. Archive of Women's Mental Health, 16, 11-18. https://doi.org/10.1007/s00737-012-0307-x

Nathanson, A. M., Shorey, R. C., Tirone, V., \& Rhatigan, D. L. (2012). The prevalence of mental health disorders in a community sample of female victims of intimate partner violence. Partner Abuse, 3(1), 59-75. https://doi.org/10.1891/1946-6560.3.1.59

$\emptyset$ verlien, C., \& Holt, S. (2019). Letter to the editor: Research on children experiencing domestic violence. Journal of Family Violence, 34(1), 65-67. https://doi.org/10.1007/s10896-018-9997-9

Postmus, J. L., Plummer, S.-B., \& Stylianou, A. M. (2016). Measuring economic abuse in the lives of survivors: Revising the Scale of Economic Abuse. Violence against Women, 22(6), 692-703. https://doi.org/10.1177/1077801215610012

Rivera, E. A., Sullivan, C. M., Zeoli, A. M., \& Bybee, D. (2018). A longitudinal examination of mothers' depression and PTSD symptoms as impacted by partner-abusive men's harm to their children. Journal of Interpersonal Violence, 33(18), 2779-2801. https://doi. org/10.1177/0886260516629391

Spitzer, R. L., Kroenke, K., Williams, J. B., \& Löwe, B. (2006). A brief measure for assessing Generalized Anxiety Disorder: The GAD-7. Archives of Internal Medicine, 166(10), 1092-1097. https://doi. org/10.1001/archinte.166.10.1092

Sullivan, C. M., \& Bybee, D. I. (1999). Reducing violence using community-based advocacy for women with abusive partners. Journal of Consulting and Clinical Psychology, 67(1), 43-53. https://doi. org/10.1037/0022-006X.67.1.43

Toews, M. L., \& Bermea, A. M. (2017). "I was naive in thinking, 'I divorced this man, he is out of my life": A qualitative exploration of post-separation power and control tactics experienced by women. Journal of Interpersonal Violence, 32(14), 2166-2189. https://doi.org/10.1177/0886260515591278

Vu, N. L., Jouriles, E. N., McDonald, R., \& Rosenfield, D. (2016). Children's exposure to intimate partner violence: A meta-analysis of longitudinal associations with child adjustment problems. Clinical Psychology Review, 46, 25-33. https://doi.org/10.1016/j. cpr.2016.04.003

World Health Organization. (2013). Global and regional estimates of violence against women: prevalence and health effects of intimate partner violence and non-partner sexual violence. World Health Organization.

Publisher's Note Springer Nature remains neutral with regard to jurisdictional claims in published maps and institutional affiliations. 